\title{
Closing the Gaps in Disaster Management and Response: Drawing on Local Experiences with Cyclone Idai in Chimanimani, Zimbabwe
}

\author{
Nelson Chanza ${ }^{1}$ Pakama Q. Siyongwana ${ }^{2}$ - Leizel Williams-Bruinders ${ }^{3}$. \\ Veronica Gundu-Jakarasi ${ }^{4}$ - Chipo Mudavanhu ${ }^{1}$ - Vusomuzi B. Sithole ${ }^{5}$. \\ Albert Manyani ${ }^{1}$
}

Published online: 27 July 2020

(C) The Author(s) 2020

\begin{abstract}
Cyclone Idai in Zimbabwe exposed deficiencies in the country's disaster management system. This study uses a phenomenological case exploration of the experiences of local residents in Rusitu Valley following cyclone-induced floods that affected the area in March 2019. Through capturing narratives of participants who were recruited through chain referrals, the research intends to understand how local actors, utilizing their local-based response systems, managed to fill in the voids that characterize disaster management practice in Zimbabwe. Results show that the participation of local "heroes" and "Samaritans," by deploying their social networks, norms, relationships, practices, and modest ingenuity, helped to speed up response times and minimize threats to lives and livelihoods. Documentation of the stories of local actors about their disaster experiences also gives a richer picture of the Cyclone Idai disaster. Although the community response system also facilitated the operation of external disaster management agencies, their premature withdrawal tended to weaken the trust and values existing in the area, and created tensions between the disaster-affected people
\end{abstract}

Nelson Chanza

nchanza@gmail.com

1 Geography Department, Bindura University of Science Education, Bindura, Zimbabwe

2 School of Biology and Environmental Sciences, University of Mpumalanga, Nelspruit-Mbombela1200, South Africa

3 Department of Geosciences, Nelson Mandela University, Port Elizabeth 6031, South Africa

4 Infrastructure Development Bank of Zimbabwe (IDBZ), Harare, Zimbabwe

5 United Nations Development Program (UNDP), Harare, Zimbabwe and other villagers. Given the delays in formal responses by the government and other external relief agencies, the practices of local actors, although spontaneous and largely uncoordinated, offer rich insights into the design and development of disaster management regimes.

Keywords Cyclone Idai · Flood disaster management - Local knowledge and action - Social networks $\cdot$ Zimbabwe

\section{Introduction}

In Zimbabwe, the past two decades have been punctuated by a series of cyclones, which have left serious impacts in the entire socioeconomic system. These events can be chronicled from the 2000 Cyclone Eline that caused 91 deaths, 357 injuries, destroyed 59,187 houses, and resulted in about 2.7 million people being affected (Brown et al. 2012). This was followed by Cyclones Japhet in 2003, Dineo in 2017, and Idai in 2019, which this study examines. Cyclone Idai hit the country on 15 March 2019, leading to missing and displaced persons; loss of lives, property, livestock, crops, and livelihoods; and destruction of infrastructure and the environment. Rusitu Valley in Chimanimani is one of the low-lying areas where Cyclone Idai left traumatic experiences in its communities. The local inhabitants are said to have utilized a collection of their local networks, values, resources, and ingenuity in responding to the disaster. Some parts of the area were completely cut off from the rest of the country for several days, as roads and bridges were damaged and communication systems were disrupted. Helicopters could not fly into the affected area due to poor visibility and the risk of crashing in the mountainous terrain that is interspaced by 
deep valley floors. The state disaster management officials and other external support services only managed to access Rusitu Valley on 20 March 2019. This means there was a five-day period in which local action is undocumented, but of significance. It is from this background that this study collected local narratives of participants who experienced the Cyclone Idai disaster at Kopa Growth Point in Rusitu. The purpose of this information collection effort was to gather evidence on the role of local action in disaster responses, which can help frame the role of local participation in disaster management systems.

Within the disaster research community, many scholars have challenged the conventional belief that the use of external expertise in disaster affected areas offers the best solution (Burton et al. 1993; Bolin and Stanford 1998; Twigg 1999; Allen 2006; Kapucu 2008; Gwimbi 2009; Varda et al. 2009; Hawkins and Maurer 2010; Zubir and Amirrol 2011; Yila et al. 2013; Misra et al. 2017; ApplebyArnold et al. 2018). Some scholars have demonstrated the utility of local action through concepts such as "social networks" (Varda et al. 2009; Islam and Walkerden 2017; Misra et al. 2017), "community participation" (Zubir and Amirrol 2011; Preston et al. 2015), "community empowerment" (Rajeev 2014), or "community-based" responses (Allen 2006; Troy et al. 2008). This study embraces these conceptual strands, but interchanges "local experiences" and "local-based" terminologies to understand how residents in Chimanimani, Zimbabwe reacted to the Cyclone Idai-induced floods.

\section{Literature Review}

Focus on the importance of local action in disaster studies continues to get traction. Locally-based action in disaster management is largely influenced by the form and strengths of social networks (Grootaert and Van Bastelaer 2002; Varda et al. 2009; Misra et al. 2017) and the culture of the affected community (Manyena 2006; Gwimbi 2009; Zubir and Amirrol 2011; Appleby-Arnold et al. 2018). It is believed that such local ties are important in strengthening community resilience and recovery from disasters (Allen 2006; Kapucu 2008; Islam and Walkerden 2017; Misra et al. 2017). The strengths and weaknesses of these local social networks deserve research attention as communities rely on them to respond to emergencies. Simba (2018) points out that local action is more than the immediate community as it also involves external players when it comes to disasters. How well the different actors blend in disaster action, however, deserves further examination. Becker (2018) stresses that integration of various players is largely dependent on the trust of and influence of external agencies. If properly recognized, for example through use of community coordination strategies that are cited by Kapucu (2008), this variable can actually enhance public response to disaster.

Hazard studies highlight how, due to a devastating disaster impact on the community and individuals, disasteraffected people are often keen to unite to confront the loss that they have suffered. For instance, following the urban flooding in Australia, McKay (1984) and Smith and Handmer (1984) show that those affected were willing to help each other. In southern Poland, Działek et al. (2014) point out that social cohesion during disasters is more significant among rural communities than in urban areas. Inhabitants from villages contact the representatives of local authorities much more often than in cities, which is attributed to the close cooperation in everyday management of agro-based livelihoods that characterizes rural communities. Alexander (2010) shares a similar observation at the grassroots level in which local authorities are expected to react to disasters first before they call for external assistance. To Troy et al. (2008), an important component of community engagement is the availability of local resources. With their readily available personnel, if given timely information (Allen 2006), local citizens can address the inevitable delay in formal disaster management assistance, since the first response always comes from local actors (Kapucu 2008). Indeed, there is substantial evidence that embraces the importance of local action in disaster management regimes although local-based action can be gender and age biased (Davern and Hachen 2006; Siyongwana et al. 2015). Moreover, political dynamics can also disintegrate existing ties, making them less effective during disasters. Such practices may also exclude people who are not members of a group network even though they are in the same geographical area, which makes such nonmembers especially vulnerable during disasters (Davern and Hachen 2006). Since local experiences are context specific, this study articulates the concept of local-based action in a setting where there are existing gaps in the national disaster management systems (Manyena et al. 2013; Oxfam 2019). A report by Oxfam (2019) reveals that although districts such as Chimanimani had their disaster risk management strategies in place, they failed to appropriately respond to Cyclone Idai due to resource limitations.

\section{The Study Area}

Chimanimani District lies in agro-ecological region 1, based on a scheme used to demarcate regional boundaries (FAO 2006). This criterion uses ecological potential centered largely on climatic and edaphic factors, where productivity diminishes as one moves from region 1 to region 
5. In region 1, annual precipitation ranges from $1000-2000 \mathrm{~mm}$, which means rainfall is not usually a limiting factor on agricultural productivity (Mugandani et al. 2012). The favorable precipitation supports a dense network of rivers and streams, most of which drain from mountains and perennial wetlands. Mean temperature ranges from 15 to $18{ }^{\circ} \mathrm{C}$, with possibilities of frost during the winter season. Altitude ranges from $142 \mathrm{~m}$ on valley floors to 2,377 $\mathrm{m}$ at mountain peaks (Chitamba et al. 2013). Long years of exposure to denudation have led to deep and steep valley slopes that explain the high velocity of rivers flowing throughout the year. This means most rivers become vicious with high erosive powers during the rainy season. The area of interest, Kopa, is a flood plain situated at the confluence of major rivers of Rusitu, Nyahode, and Chipita in the Rusitu Valley. This junction makes the area highly prone to riverine flooding (Fig. 1).

Farming is highly specialized and diversified, characterized by an assortment of horticultural produce (mainly potatoes, bananas, mangoes, sugarcane, among others), maize production (mainly for subsistence), and plantations (tea, coffee, and timber). The main form of livelihood of the peasantry population in the study area is smallholder banana farming. Commercialization of fruit production is mainly stymied by poor earth roads that get muddy and slippery in the rainy season. Most produce rot before getting to the market or are sold cheaply in local markets.

Chimanimani District has a population of 134,940 people, who are largely rural $(95 \%)$ with a $95 \%$ literacy rate (ZimStat 2013). About 1,600 households, containing about 9,600 people were directly affected by Cyclone Idai in Rusitu Valley (Copernicus 2019). The Kopa settlement, which was completely destroyed by floods, had about 200 families. Although the district is run by the Chimanimani Rural District Council (RDC) as governed by the Rural District Councils Act, there is a de facto customary leadership arrangement in terms of the day to day affairs of the community. In this system, a headman (sabhuku), who reports to a ward chief (sadunhu/mambo), who then reports to a district chief (ishe), in this hierarchical order, are responsible for observing the local norms, values, and culture. The RDC's role, however, is particularly evident in rural planning and development of service centers such as Kopa. In practice, this dual system may create tension between the traditional leadership and the RDC system (Mararike 2011). The establishment of the Kopa settlement is believed to have occurred against the local tradition. The settlement was established in an area traditionally used for livestock grazing and it drew settlers from other places outside Chimanimani. Yet the local residents regard their customary laws as long-standing and tested. The people in

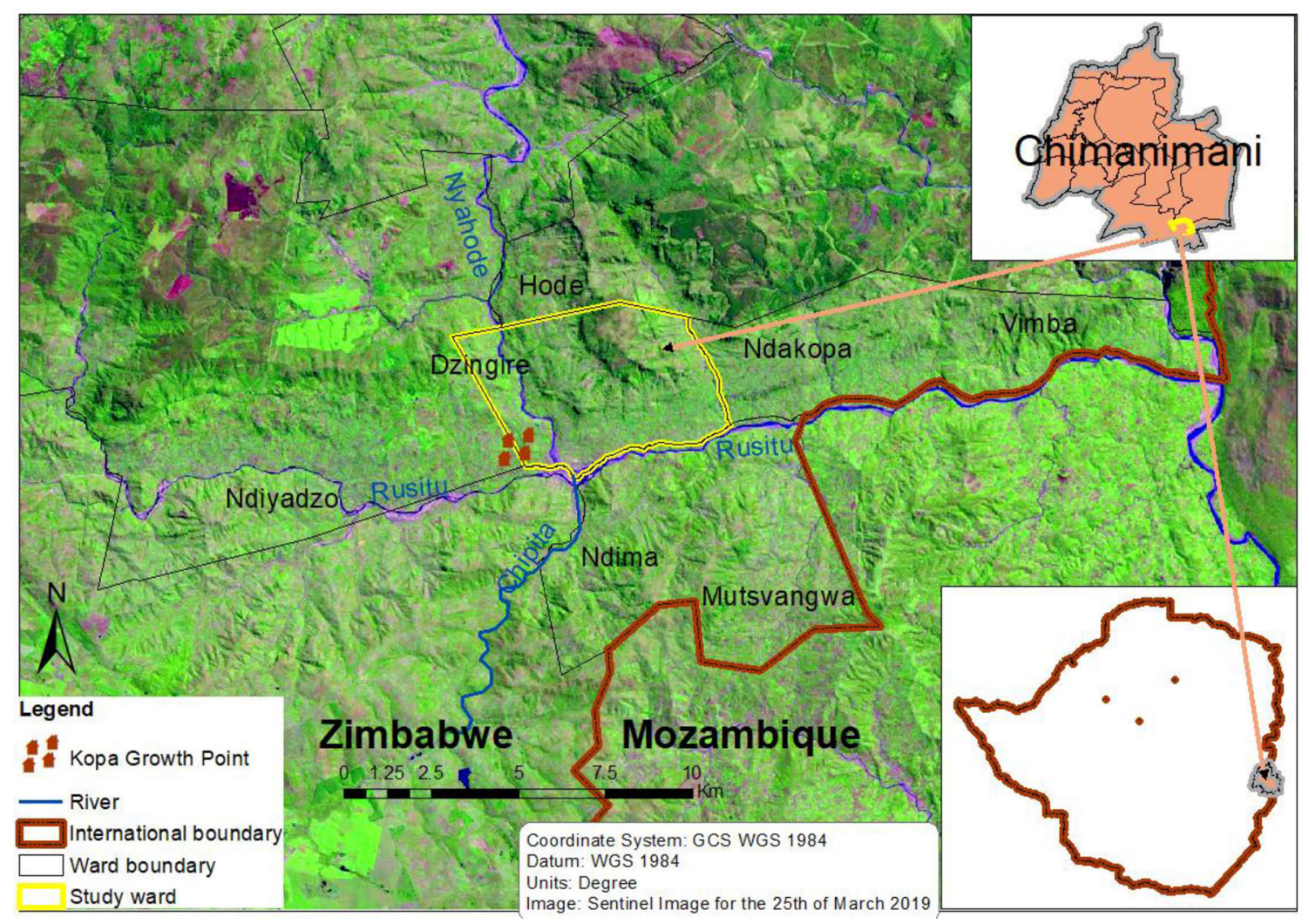

Fig. 1 Location of the study area in Chimanimani District, Zimbabwe 
Chimanimani speak Ndau, a dialect of the dominant Shona language in Zimbabwe. The local population also has a long history of forced displacement from good arable lands to give room for white settler plantation estates during the colonial era. As such, most of the settlements are found in ecologically (mostly in mountainous terrain) and hydrologically (close to rivers and in floodplains) sensitive areas, and most of the families have a large appetite for better quality land. Clearly, this background makes the community highly vulnerable to weather-related hazards such as floods and landslides.

\section{Methodology}

This study uses a case study qualitative examination of experiences and roles of local people in the Cyclone Idai disaster. The study area was chosen because it was one of the hotspots of the Cyclone Idai disaster in Zimbabwe. The case analysis was complemented by a phenomenological approach in which the lived experiences of the participants could be best understood. Fieldwork was done between 10 December 2019 and 31 January 2020.

Since the study intended to understand the local experiences, the role of local actors, and the nature of interventions made, it was necessary to interview both survivors and community members who offered various forms of assistance to the survivors. Accordingly, participants were categorized as survivors and helpers during the flood; the study refers to the latter group as "heroes"-a term used by the local villagers to describe the challenging role played by these people during the cyclone. "Community Samaritans" was adopted to describe the nature of help they offered to the survivors, including the homeless, by a specific category of community members. A total of 17 local citizens participated in the study, broken down as six survivors, five heroes and six community Samaritans. These participants were recruited through chain referrals, where an identified participant would refer to other key people whose narratives would be most critical to the study's objectives. Thus, the size of participants was determined through theoretical sampling until theoretical saturation was attained. Interview sessions ranged from 40 to $90 \mathrm{~min}$ and were largely conducted at participants' homes. Shona and English were the languages used in interviews. In the former case, interview transcripts and notes were later translated into English.

In order to show the extent of cyclone damage, the study also observed the once built up Kopa settlement and captured it in photographs. Thematic and content analysis was used to analyze primary data. Given the ethical implications of interacting with people who were affected by a disaster, participants' consent was first obtained after explaining the purpose of the study and how they were expected to participate. Confidentiality and anonymity were maintained throughout the study. The study only dealt with adults above 18 years of age. No cases of discomfort emerged during interviews and all participants successfully completed interview sessions. The study protocol observed the ethical guidelines provided by the Bindura University of Science Education.

\section{Results}

From the analysis of accounts of the participants' lived experiences with the Cyclone Idai disaster, a number of themes emerged, which were used to structure the results. These include narrations of how the villagers had perceived the hazard and the impact they felt during and after the disaster; how they collectively drew upon their knowledge and local networks to rescue those who were trapped by the floods, search for those who died, and treat those who were injured; how they attended to the welfare of survivors after the disaster; and how they used such networks to help in the coordination of external-based response and recovery practices.

\subsection{Experiences with Cyclone Idai}

The local villagers visualized and described the before and after situation on the residential area. The settlement was replaced by huge rock boulders as shown in Fig. 2. Participants were unanimous that the impact was beyond comprehension. To them, everything was lost, including people's valuables, money, livelihoods, lives, and infrastructure.

The insights by the five main participants in the rescue operations reveal how the disaster happened. The disaster occurred at around 10 p.m. on the night of 15 March 2019, usually the time when people would have fallen asleep. The interviewees corroborated that the ability to evacuate was compromised by the darkness. Owing to fear that their houses could be flooded, however, most of the residents kept awake and closely monitored the situation. It is also important to note that although most people remained awake, as evidenced by their capability to move out of their houses and assemble at a police station, communication systems were reportedly down, electricity had gone off, there was no mobile network and phones were inoperative. Coupled with the torrential rains were heavy winds and darkness, so it was very difficult for the people to find escape routes. One of the survivors supported this saying: "We only saw water flooding into houses and it was too late for us to evacuate. You could only see after lightning flashes that water had abandoned its channel, cutting off 


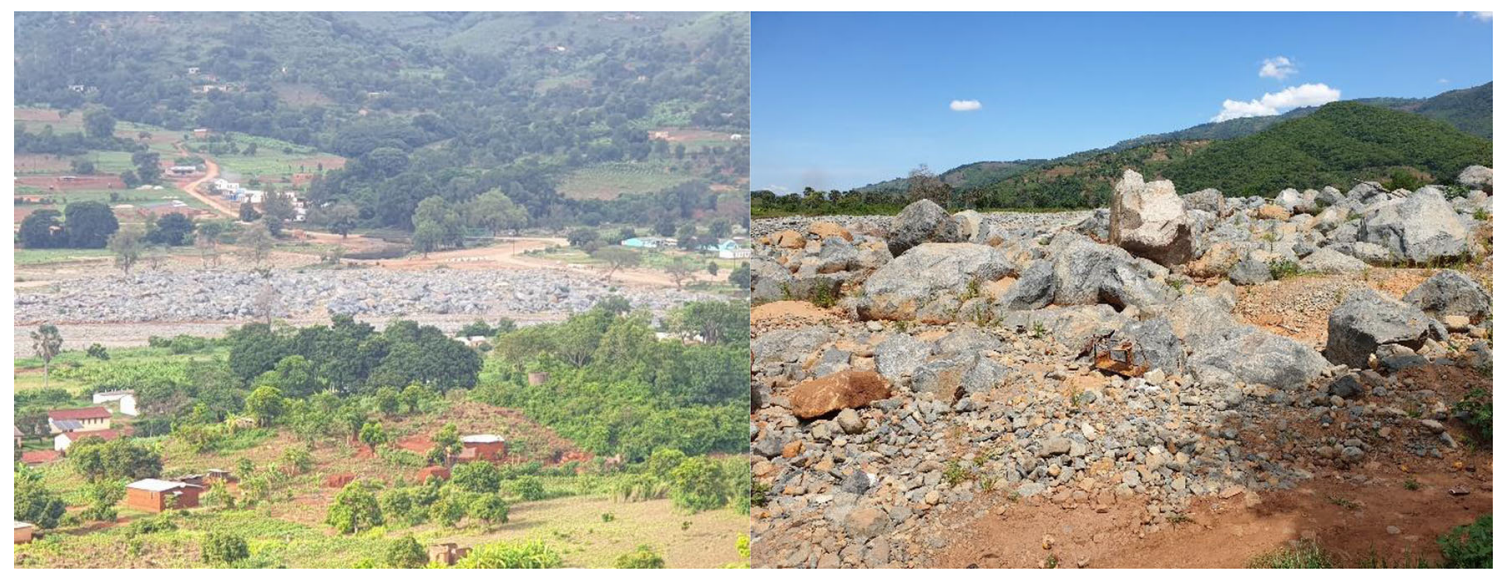

Fig. 2 The impacts of Cyclone Idai at Kopa Growth Point, Chimanimani District, Zimbabwe. Elevated view of the once built up Kopa settlement now replaced by boulders (left) and zoomed in image of

the settlement to produce an island and we could not move out" (Survivor 1). Most of the people managed to heed the call to assemble at a police station, where water had not yet reached. Over 200 people are believed to have sought refuge at the police station. Of these 200 people, about 40 survived, 5 bodies were recovered and the rest remain missing persons and their whereabouts have not been established up to this time of publication (June 2020). There were several reasons why the survivors felt the police post was still safe despite all the warnings given (Table 1).

\subsection{Roles of Local Actors Before, During, and After the Cyclone}

The first actors to respond to the Cyclone Idai disaster in Rusitu Valley were the local shop owners and shop attendants. Their retail shops were located some distance from the area affected by the floods. The delay in accessing the area by external disaster management authorities gave them an opportunity to deploy various locally-based response practices. The engagement of these actors in activities to save lives, search for missing persons, or attend to the welfare of those in need happened at different stages of the disaster. Interventions also occurred at individual, family, and village levels. The individuals who actively participated in rescue operations were clearly evident at the onset of the impending disaster. Although they were individually motivated by the need to save life, their actions were collective. One of the rescuers revealed that, "After observing that the settlement was now an island cut off by the bursting Nyahode River, with people trapped and failing to cross to safer ground, I felt it was not safe for me to get there alone, but had to seek the company of others who could also witness the event" (Hero 2). Hero rock deposits after floods (right). Source: Field photographs by Tabitha Chanza, 2 January 2020

3 weighed in saying, "We had to motivate each other, assuring that it was possible to rescue the people who were trapped despite the high risk." These statements reveal that individuals were collectively driven by the need to save life. In other words, after realizing the urgent need to intervene to save lives, they felt that their joint ideas would offer the best form of assistance under such an emergency situation. According to the survivors, there were also individuals who demonstrated care by offering to assist those mothers who found it difficult to escape with children. These persons, mostly women, were reported to have helped in taking some of the children to ease the burden on mothers who were struggling with more than two children. It later came out that some of these children actually survived while their parents perished.

From the quotations given by survivors and the community Samaritans, the participation of families was largely noticeable at the level of meeting the welfare of the survivors, particularly during the emergency phase. Their narration indicated that, because the external safety nets took a long time to be clearly established, the role of some families was still predominant beyond the emergency period. Thus, the collective role of the villagers was evident from the time the disaster was experienced all the way into the recovery phase. Respondents also expressed the view that villagers teamed up to search for missing persons for several days, including joining soldiers who were deployed to carry out search and rescue operations more than $100 \mathrm{~h}$ after the floods subsided. Through their collective effort, the villagers managed to identify five bodies that were either buried in sand or thrown out of the river. Although the worst affected village was Dzingire, other villagers from Ndiyadzo, Ndima, Hode, Ndakopa, Mutsvangwa, and Vimba also teamed up in what is locally referred to as chihwirangwe, the act of addressing a 
Table 1 Reasons for disregarding local early warnings. Source: Survivors' responses 2019

\begin{tabular}{|c|c|}
\hline Reason & Explanation $^{\mathrm{a}}$ \\
\hline Fear and confusion & $\begin{array}{l}\text { Some people felt it was still safer than risking their lives through the rope }{ }^{\mathrm{b}} \text { at a time when the water level was very } \\
\text { high } \\
\text { The major challenge was the mixed thoughts and reactions about the safety and efficacy of the rope, otherwise } \\
\text { more people could have been saved }\end{array}$ \\
\hline $\begin{array}{l}\text { Experience with previous } \\
\text { cyclones }\end{array}$ & $\begin{array}{l}\text { There were also mixed thoughts, with some strongly believing that the floods would quickly recede, while the } \\
\text { voices of those who saw the need to evacuate tended to be weaker } \\
\text { They believed that the water had reached its maximum levels and based on previous experiences with past events, } \\
\text { the floods would soon crest and recede }\end{array}$ \\
\hline $\begin{array}{l}\text { Reluctance to leave } \\
\text { valuables }\end{array}$ & $\begin{array}{l}\text { Some people had valuables and were keeping large amounts of money from their businesses. They were not } \\
\text { prepared to leave their valuables } \\
\text { Some thought they could find an opportunity to take their valuables with them } \\
\text { Feeling that they could not leave their houses as their valuables could be stolen }\end{array}$ \\
\hline Hope in external evacuation & $\begin{array}{l}\text { Hope that a helicopter would rescue them the following morning } \\
\text { There was debate between those who strongly felt that the rope could save them and those who anticipated that the } \\
\text { helicopter would be called in }\end{array}$ \\
\hline Dominance of key persons & $\begin{array}{l}\text { There was a problem of public figures who tended to be listened to more regardless of the usefulness of their } \\
\text { advice } \\
\text { Many would have been saved through the rope, but people have a tendency to argue instead of taking action } \\
\text { There was a sense of hope and comfort in the view of the majority and influential people, but this misled them and } \\
\text { turned out to be very unfortunate } \\
\text { The people felt they were safer by being at a police camp than anywhere else, although the place was also at risk of } \\
\text { flood } \\
\text { A certain police constable, reportedly drunk, was blamed for giving false hopes to the desperate people that the } \\
\text { floods were not going to harm them }\end{array}$ \\
\hline
\end{tabular}

${ }^{a}$ Each respondent gave various reasons but these were classified according to emerging themes

${ }^{\mathrm{b}} \mathrm{A}$ detailed description of how the rope was used for evacuating survivors is given in Sect. 5.4

problem together. It was also reported that villagers walked for up to $30 \mathrm{~km}$ downstream into Mozambique searching for bodies of missing persons. These operations were led by traditional leaders.

\subsection{Local Early Warnings and Early Action}

There were mixed reactions in the way people perceived early warnings and this affected their actions. The warnings considered in this study are those given by the local residents after sensing the hazard. There was evidence that the local villagers had considered the warnings they received from mainstream media and government authorities as general and not quite useful in their area. It was reported that the message about Cyclone Idai, and how it was projected to affect their area, did not effectively filter to the community. This is captured in a testimonial by one of the study participants saying;

We had heard about the cyclone, but people just thought it was the same cyclones that were previously experienced. We simply thought that these were just social media news. Had it been that warnings were given earlier specifying the seriousness of the cyclone and its impacts, people would have vacated their houses when it was still safe to do so. (Survivors 3)

However, one participant felt that the government had done enough in advising people to take precautionary measures: "That teachers and headmasters had dismissed learners instructing them to inform their parents or guardians to move out from riverine and low-lying flood risk areas, but ended up ignoring the same information themselves is very disturbing" (Community Samaritan 1). This is quite unfortunate when one discovers that school heads and teachers were counted among the missing persons. The corroboration by two of the participants clearly explains the failure to take early action by some community members.

Some people took it lightly despite the warnings and education given, arguing that the previous cyclones did not seriously affect the community, but simply came and pass. [...] It appears people were more concerned about the assets they had accumulated and were not willing to just leave their valuables. (Survivors 4 and 6) 
The local early warnings were largely based on information that few individuals heard from news channels or from social media. It was reported that on the day of concern, people met in small groups discussing Cyclone Idai, but they had a feeling that, like other previous events, the cyclone would just be an event in passing. This means the community had generally developed a wait and see attitude and were only ready to take measures upon observing the phenomenon. However, the villagers were not just passive as confirmed by the responses presented in Table 2.

These reports by the participants were actually part of the local early warnings that they used in devising rescue operations. One of the rescuers added that he had to defy the harsh weather of strong winds, heavy downpours, and darkness, rushing to the mumadhomeni area where he observed a large group of people camped at the police station and crying for help. He had to quickly hurry back to the shops to mobilize the assistance of other rescuers. It was this vigilance and quick decision that saved the reported 40 people who survived the floods.

\subsection{Rescue and Search Operations}

The people who were worried about the safety of the residents trapped by floods in the mumadhomeni area did not become complacent. According to the interviewees, they quickly mobilized each other to form a group of five brave men who devised modest but critical rescue operations. Given the risk of the activity they embarked on and their level of dedication to save lives, the villagers describe these rescuers as heroes in their own belief.

This group of heroes evolved a specific procedure by which they launched their rescue effort. They conceived the idea of using a rope after realizing that the lives of people who were crying out for help were in their hands. The trio was unanimous about the idea of using a rope to rescue the trapped people. They were also joined by two young men who had their families trapped by the floods. They rushed to a business person's hardware store where they knew they could secure a rope. The instruction to the shop attendant was short and clear, "Bring out a rope, people are dying mumadhomeni." There was no time for discussion. They also took with them torches [flashlights] to illuminate the area. The ropes were tied on one end around a mango tree on the roadside stretching to a distance of about $80 \mathrm{~m}$ to the other end, where it was tied around an anti-burglary iron rod protecting a window. The ropes were firmly fastened using wire that was obtained from the shops. The idea was to make sure that more people could, as quickly as possible, use the rope for stability at the same time they crossed the flowing stream. The heroes positioned themselves at different points along the rope to coordinate the operation and to assist those who had difficulties in crossing on their own. After noticing that the pressure of the water was increasing and they could risk their own lives, one of them gave a wild cry instructing that they should immediately abandon the activity and move out of the water. Suddenly, there was a huge wave of water, reported to be the height of a building, that covered the whole place and this ended the operation. The evacuation took only about $20 \mathrm{~min}$ and they had managed to evacuate between 25 and 30 people. The other group of survivors was saved on the following day.

It is critical to note that the rescue operation, although it happened for less than half an hour, was the only method that saved people. The heroes were quite skillful in tying the rope in order to ensure its firmness so that it would be safe for anyone using it. The idea of the rope was to enable an easier and faster way of evacuating the people particularly those who could not cross the floods on their own. The main challenge that the heroes faced was to handle mixed reactions from the crowd. There were those who doubted the safety of the rope as indicated in Table 1; also some influential people misled the group into believing that the situation was still manageable. The rescuers stated that

Table 2 Statements by interviewees on local warnings. Source: Primary data 2019

\begin{tabular}{ll}
\hline Interviewee & Response \\
\hline Hero 2 & $\begin{array}{l}\text { I developed the habit of assessing the water levels from a young age. So the same habit triggered me during the middle of the night } \\
\text { to check the water levels in Nyahode River } \\
\text { People had actually spent the large part of the day monitoring the water levels of Nyahode and Rusitu Rivers. By around } 6 \text { p.m., } \\
\text { the water was just about } 1 \mathrm{~m} \text { below overflow level at the bridge over the Nyahode River. The only problem is that no one took a } \\
\text { step further to advise the people to vacate from the mumadhomeni }{ }^{c} \text { area }\end{array}$ \\
Hero 3 & $\begin{array}{l}\text { I had knowledge that as long as it was still raining, the flooding situation would worsen. When I heard the sound I rushed to check } \\
\text { if the residents of mumadhomeni were safe }\end{array}$ \\
Hero 5 & I woke up after a feeling that the situation may not be well with people staying at mumadhomeni
\end{tabular}

${ }^{\mathrm{c}}$ The affected area was popularly known by this name. A name given after the first houses developed in the late 1980s belonged to the agricultural advisory service officers or demonstrators, known as madhomeni in the local language 
there was little time to listen to people's arguments, but the instruction was: "We have erected a rope. Everyone rush to the rope for your safety" (Hero 1). It is believed that if people had taken the instruction more seriously, more people could have survived.

Thoughts about what pushed participants to take part in such a risky operation, are presented in Fig. 3.

The rescue operation continued on the following day when more people joined to search for missing persons and to identify and rescue other survivors. A few of these survivors were found hanging on trees or on some small islands. One of the rescuers said;

We extended the rope that was tied with a rock at its end so that it could reach the target. We then asked the people to tie themselves around the waist, then we pull the person. For those who could not make it on their own, one brave person would swim to rescue the person by the waist and those outside the water to pull out. (Hero 5)

About 15 people were reported to have been rescued using this technique. The local searchers managed to identify five bodies before they received support from external based searches. However, the latter's intervention did not yield any results.

\subsection{Meeting the Welfare of Survivors}

Depending on the circumstances of those affected by the cyclone, the needs of survivors were both immediate and gradual. The survivors spent the night in shops or verandas of business people until the following morning when prompt arrangements were then made for their welfare. However, the immediate needs were not properly coordinated, but spontaneous. These were largely meant to meet

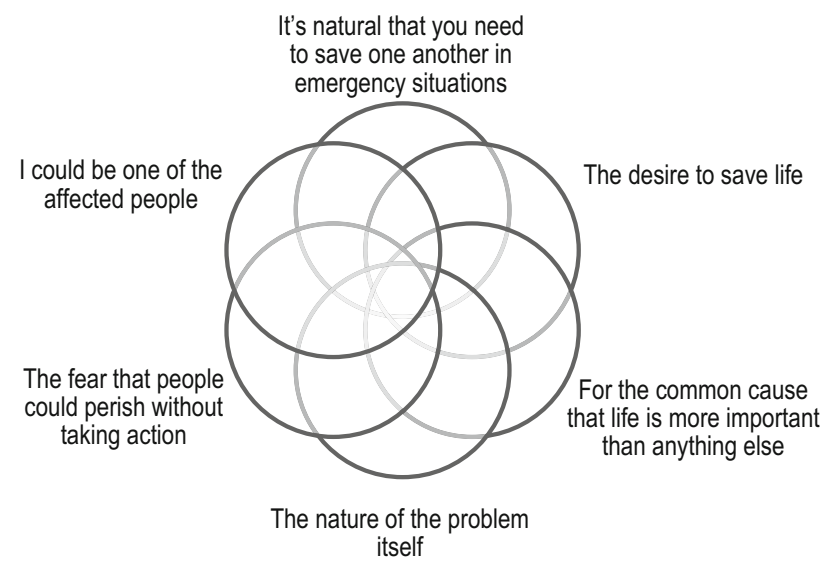

Fig. 3 Mapping motivational factors of community rescuers in Kopa Growth Point, Chimanimani District, Zimbabwe. Source: Participants' responses in 2019 field interviews and notes urgent needs such as clothes, food, shelter, and nursing the wounded. As one participant puts it, "I was awakened by loud cries of children who had stormed my house, fleeing the floods at Kopa. I had to quickly organize some clothes from my family members as these children were almost naked" (Community Samaritan 2).

Donations towards the needs of the survivors were overwhelming. One survivor reported that, "People moved in with various items to ease the problem. You could not even remember who had given you what exactly, but assistance came from various sources" (Survivor 2). The caring for the survivors could not be endured alone by those who volunteered to keep the homeless at their houses, but it was a collective responsibility. The demonstration of oneness during critical times of need can be best understood in a statement by Survivor 6 saying, "During those days when villagers teamed up to search for missing persons, no one could afford to sleep. It was a joint effort by both women and men, the young and the old." In some cases, the homes were used as meeting places by relatives and some church members who would have come from other areas to console those whose relatives had gone missing. This took up to 2 weeks until all the hopes of finding the missing persons were lost. Clearly, there were high levels of accepting the problem, since some places resembled funeral scenes as more and more relatives of survivors came from different places. The survivors reported that they spent up to a month being accommodated in homes of relatives, friends, and other villagers as government arrangements took so long to be put in place.

It is also important to note the spirit of selflessness exhibited by some of the caregivers who accommodated the survivors. One of them was able to accommodate as many as 18 people at a time when food was running out. Since not everyone was able to accommodate the survivors, some villagers followed up with those families that had volunteered to keep the survivors. One of the participants indicated, "My wife also went to one of the places where most survivors were accommodated. She assisted with preparing food and bathing and clothing kids" (Community Samaritan 5). Although these community helpers were not trained as social workers, this study established that they also developed the necessary knowledge and skills of addressing the psychosocial needs of the survivors. One of the participants reported that, "We also educated the community and other children against use of such discriminatory terms as "victims" and "orphans" of Cyclone Idai. Instead, the use of terms such as "missing persons" gave hope to those who had lost their loved ones" (Community Samaritan 3).

The long-term care of survivors was still reported at the time of research. This was mainly in the form of continued psychosocial support from some members of the 
community who always check how the survivors were coping. The evidence that psychosocial care can go on for extended periods of time in a post-disaster environment is reported by one of the community helpers:

As a teacher, I have a strong feeling that home environment is more suitable for school going children than tents. Life in tents, particularly at a growth point is not appropriate for school children. This realization has made me to continue keeping some of the children here. (Community Samaritan 1)

The aftermath of the cyclone required the community residents to be innovative and to rely on local resources in confronting the changing situations. When floods destroyed bridges, Kopa Growth Point became inaccessible. This hampered efforts to support survivors, conduct search and rescue operations, and assess the impact of the damage. By deploying their local ingenuity, the villagers managed to establish a temporary footbridge that enabled access to Kopa. In addition, the first access road was the initiative of local citizens who, with support from a local business person, removed all the barricades that prevented access to Kopa from Chipinge Town.

\subsection{Linkages with External Agencies}

The Cyclone Idai disaster created opportunities to develop different forms of linkages, that is, within villages, between villages, and with external disaster response agencies. The disaster unlocked external development assistance and managed to draw the attention of both government agencies and nongovernmental organizations. Today there is a feeling that Cyclone Idai has opened up avenues for the participation of development partners in development projects, particularly the upgrading of road infrastructure.

The participation of government and donor agencies was facilitated by the local individuals. One of the study participants reported that he was tasked by the Civil Protection Department to generate a database of missing people, people who had died, the homeless, and those displaced from all the affected villages. Commenting about the entry of external players, Survivor 3 expressed dissatisfaction about the treatment native villagers sometimes got: "Soldiers whipped us while we were waiting in queues to get relief items. Their arrangement should have separated the disaster-affected people from the rest of the villagers." Hero 1 also reported that the influx of the donors initially created chaotic scenes that only ended after clear aid distribution structures were established with the help of representatives of the local community. However, from the perspective of the villagers, the influx of the external agencies has actually done more harm than good. They argued that their untimely withdrawal, after feeling that the external agencies and institutions had done enough, actually created divisions between the survivors and the rest of the villagers. There was a strong feeling in the community that the survivors' welfare was going to be wholly met by external agencies, yet the support simply ended prematurely.

\section{Discussion}

Against a backdrop of a weak disaster management and response system in Zimbabwe, this study gives several insights into the roles of local actors and the challenges they face when experiencing disasters. When confronted with an emergency, local communities do not remain complacent or wait for directions from national disaster management professionals. Instead, local actors use their personal networks to give warnings, engage in search and rescue operations, assist survivors in critical need, and organize structures that are later used by exogenous agencies. This study has shown that although such local interventions are largely based on modest means of communication, local knowledge and ingenuity, collective resources, and local networks, but the cumulative action these interventions initiate can significantly help in minimizing disaster impact. Given the lengthy lag time of over $100 \mathrm{~h}$ before the appearance of external disaster management authorities, the impact could have been more severe as more lives would have been lost.

One area where local action can feed into our understanding about disasters is the detailed accounts given by the people who directly experienced the events. In the case of Cyclone Idai in Chimanimani, the rich accounts about how the disaster occurred by those observing, witnessing, experiencing, and participating in the flood have been useful in informing subsequent interventions by the disaster management community. Our study has shown that the impact of the cyclone disaster cannot be fully documented without capturing the lived experiences of survivors and other community members who witnessed the disaster. It is from such experiences that the narratives of local informants can give pointers to the need to strengthen response systems, in conjunction with external disaster management authorities (Allen 2006; Kapucu 2008; Zubir and Amirrol 2011). From the perspectives of the local people themselves, such experiences have given them the opportunity to test their community-based interventions against a background of the weak disaster response culture cited by Bongo and Manyena (2015). In a similar observation, Allen (2006) and Troy et al. (2008) noted that local engagement can provide a database of information useful for disaster responses. Corroborating Kelman's (2019) observations that actions to prevent disasters can be voluntary, this study 
indicated that people do not remain passive when they face an impending disaster, but rather take actions to minimize impacts.

Within this collection of local-based interventions, gender differentiation was very evident. Youth, women, and men were actively involved, although playing different roles at different stages of the disaster. The role of men tended to be prevalent during evacuation and rescue procedures, while women were largely active in saving children during and after. However, Molyneux (2006) and Bene et al. (2012) were worried about the strong bias of women as mothers that, they argued, gives them an extra burden of care. Within the practice of local responses, there are people who go an extra mile in providing care for those affected by disasters. These are men and women whose role can be seen ranging from giving early warnings to taking early action to address the welfare of children, the elderly, and the injured. Such people can be critical pillars in community-based disaster risk reduction (DRR). This observation resonates with the thoughts of Appleby-Arnold et al. (2018) that integrating shared local values and experiences may be particularly effective in strengthening DRR systems.

A critical factor shaping local responses is the guidance and directions given by the local leadership through their use of customary laws, which are usually venerated in rural communities. A typical case commonly in practice in Zimbabwean rural societies is the need to pause individual activities in order to collectively join the bereaved family. The study found that this demonstration of oneness was not limited to the short-lived burial of the deceased, but spanned the long post-disaster situation in the form of attending to the welfare of survivors. Similarly, Gwimbi (2009) argues that indigenous cultures encourage local participation, build self-reliance, and empower communities affected by disasters.

Potentially, the use of local networks can strengthen disaster management systems in the area of early warning systems and early action. According to Yila et al. (2013), this is particularly critical where public response systems tend to be weak in their praxis as in the case of Cyclone Idai responses in Zimbabwe. Kapucu (2008) and Alexander (2010) similarly note that, in emergency responses, community members react first before external actors. In this study, however, there were problems in complementing local early warnings with early action because the affected people had mixed feelings about the usefulness of warnings given by their own community members. Due to limited awareness and underestimation of flood risk, Speller (2005) and Burningham et al. (2008) also observe that residents tend to adopt a passive attitude towards floods. This study observed, however, that the desire to act collectively did not weaken even when villagers were hit by the floods.
Fundamentally, the deployment of locally-based interventions utilizes locally available resources, which makes it quick to respond particularly during the emergency phase of the disaster. This study indicates that such interventions can establish modest operations and technologies that are understood by all the people involved. Twigg (1999), Troy et al. (2008) and Lunga (2015) also note the opportunity to use locally available resources, which allows active participation, inclusivity, and confidence building among community members. Aside from confidence building, particularly by the heroes who saved lives, the local inhabitants also had the chance to learn about the disaster (Bolin and Stanford 1998; Preston et al. 2015). Zubir and Amirrol (2011) stress that community-based approaches are adaptive, as they can withstand hard situations during and after the disaster.

It was also clear that community members did not exclude each other based on their groups. The study actually showed that the group division of the local businesspersons, churches, and farmers was not distinct, but they indiscriminately assisted each other during the evacuation, emergency response, and recovery. The only form of cleavage existed later between the survivors and the general villagers and it arose following the (mis)treatment of the two groups by external aid agencies. Coupled with the donations of food and other items that streamed into the community during the emergency phase of disaster response, albeit very short-lived, the community was highly expectant of a continuation in aid. However, the situation had left another form of disaster that created divisions between survivors (who used to be prioritized by aid) and the general community, with individuals and families, who felt that they had done more towards assisting the survivors. Inarguably, these external interventions tended to weaken the once existing social cohesiveness. There is now fear that those heroes and other villagers who initially met the welfare of survivors, but whose roles were not clearly recognized by external disaster management agencies, may not be motivated to offer similar assistance in future disasters. If this situation is not handled carefully, particularly at the point of integrating local initiatives with external interventions, there are indications that intervention can weaken community relations and become itself a driver of vulnerability to disasters. This thinking corroborates that of Yila et al. (2013) who stated that community cooperation creates cohesiveness and resilience that is more reliable and sustainable than the characteristically short-lived participation of outsiders. 


\section{Conclusion}

Emerging from this study is the observation that there were deficiencies in responding to the Cyclone Idai disaster in Chimanimani. To some extent, these voids were filled in by the participation of the local villagers who used their local networks to assist each other throughout the disaster. The portfolio of locally-based actions helped in minimizing the disaster impact. Accordingly, there are many opportunities that local insights, experiences, and practices offer in shaping the practice of disaster management in situations where there are inherent delays or gaps in external disaster responses. Although the eventual entrance of external agencies tended to weaken the trust and cohesion built in the community, the use of social networks facilitated the operations of external players during the emergency response phase and the restoration phase of the disaster. Aside from enhanced knowledge in strengthening disaster management regimes, such experiences also allow meaningful participation of local actors in disaster management and response. The relevance of such locally-driven disaster interventions deserves special consideration, particularly given the limitation in mainstream disaster practice in Zimbabwe. This gap can be addressed through systematic development of a national early action approach at the local level to supplement national delayed action and improve the overall mitigation and reduction of disaster risk.

Acknowledgements We wish to thank all the participants in Rusitu Valley who took their time to share their experiences about the Cyclone Idai disaster. Shepherd Chanza assisted in identifying locations of research participants while Tabitha Chanza helped in recording interview transcripts and taking photographs. Individual researchers collectively contributed to finance the field work activities.

Open Access This article is licensed under a Creative Commons Attribution 4.0 International License, which permits use, sharing, adaptation, distribution and reproduction in any medium or format, as long as you give appropriate credit to the original author(s) and the source, provide a link to the Creative Commons licence, and indicate if changes were made. The images or other third party material in this article are included in the article's Creative Commons licence, unless indicated otherwise in a credit line to the material. If material is not included in the article's Creative Commons licence and your intended use is not permitted by statutory regulation or exceeds the permitted use, you will need to obtain permission directly from the copyright holder. To view a copy of this licence, visit http://creativecommons. org/licenses/by/4.0/.

\section{References}

Alexander, D. 2010. The L'Aquila Earthquake of 6 April 2009 and Italian government policy on disaster response. Journal of Natural Resource Policy Research 2(4): 325-342.
Allen, K.M. 2006. Community-based disaster preparedness and climate adaptation: Local capacity-building in the Philippines. Disasters 30(1): 81-101.

Appleby-Arnold, S., N. Brockdorff, I. Jakovljev, and S. Zdravković. 2018. Applying cultural values to encourage disaster preparedness: Lessons from a low-hazard country. International Journal of Disaster Risk Reduction 31: 37-44.

Becker, P. 2018. Dependence, trust, and influence of external actors on municipal urban flood risk mitigation: The case of Lomma Municipality, Sweden. International Journal of Disaster Risk Reduction 31: 1004-1012.

Bene, C., R. Godfrey-Wood, A. Newsham, and M. Davies. 2012. Resilience: New Utopia or New Tyranny? Reflection about the potentials and limits of the concept of resilience in relation to vulnerability-reduction programmes. IDS working paper 405. Brighton: Institute of Development Studies.

Bolin, R., and L. Stanford. 1998. The Northridge Earthquake: Community-based approaches to unmet recovery needs. Disasters 22(1): 21-38

Bongo, P.P., and S.B. Manyena. 2015. From "government" to "governance": Tensions in disaster-resilience leadership in Zimbabwe. Jàmbá: Journal of Disaster Risk Studies 7(1): Article 188.

Brown, D., R. Chanakira, K. Chatiza, M. Dhliwayo, D. Dodman, M. Masiiwa, D. Muchadenyika, P. Mugabe, and S. Zvigadza. 2012. Climate change impacts, vulnerability and adaptation in Zimbabwe. Climate change working paper 3. London: International Institute for Environment and Development (IIED).

Burningham, K., J. Fielding, and D. Thrush. 2008. It'll never happen to me: Understanding public awareness of local flood risk. Disasters 32(2): 216-238.

Burton, I., R.W. Kates, and G.F. White. 1993. The environment as hazard, 2nd edn. New York: Guilford Press.

Chitamba, J., P. Manjeru, C.C. Chinheya, N. Mudada, and M. Handiseni. 2013. Plant-parasitic nematodes associated with banana (Musa spp.) in Rusitu Valley, Zimbabwe. Nematropica 43(1): 113-118.

Copernicus. 2019. Flood post-event situation. Rusitu Valley, Zimbabwe. https://emergency.copernicus.eu/mapping/system/files/ components/EMSR349_05RUSITUVALLEYNORTH_ 02GRADING_MAP_v1_300dpi.pdf. Accessed 19 Feb 2020.

Davern, M., and D.S. Hachen. 2006. Social network structure and job mobility. American Journal of Economics and Sociology 65(2): 269-293.

Działek, J., W. Biernacki, and A. Bokwa. 2014. Impact of social capital on local communities' response to floods in southern Poland. In Risks and conflicts: Local responses to natural disasters, ed. A. Neef, and R. Shaw, 185-205. Bingley: Emerald Publishers.

FAO (Food and Agriculture Organization). 2006. Zimbabwe's natural regions and farming systems. http://www.fao.org/3/a0395e/ a0395e06.htm\#bm06. Accessed 29 May 2020.

Grootaert, C., and T. Van Bastelaer (eds.). 2002. Understanding and measuring social capital: A multidisciplinary tool for practitioners. Washington, DC: The World Bank.

Gwimbi, P. 2009. Linking rural community livelihoods to resilience building in flood risk reduction in Zimbabwe. Jàmbá: Journal of Disaster Risk Studies 2(1): 71-79.

Hawkins, R.L., and K. Maurer. 2010. Bonding, bridging and linking: How social capital operated in New Orleans following Hurricane Katrina. British Journal of Social Work 40(6): 1777-1793.

Islam, R., and G. Walkerden. 2017. Social networks and challenges in government disaster policies: A case study from Bangladesh. International Journal of Disaster Risk Reduction 22: 325-334. 
Kapucu, N. 2008. Collaborative emergency management: Better community organising, better public preparedness and response. Disasters 32(2): 239-262.

Kelman, I. 2019. Axioms and actions for preventing disasters. Progress in Disaster Science 2: Article 100008.

Lunga, W. 2015. The inclusion of indigenous knowledge systems into disaster risk reduction policy: The case of Zimbabwe. Ph.D. thesis. Potchefstroom: North West University.

Manyena, S.B. 2006. The concept of resilience revisited. Disasters 30(4): $433-450$

Manyena, S.B., E. Mavhura, C. Muzenda, and E. Mabaso. 2013. Disaster risk reduction legislations: Is there a move from events to processes? Global Environmental Change 23: 1786-1794.

Mararike, C.G. 2011. Survival strategies in rural Zimbabwe: The role of asset, indigenous knowledge and organisation. Harare: Best Practices Books.

McKay, J.M. 1984. Community response to hazard information. Disasters 8(2): 118-123.

Misra, S., R. Goswami, and R. Jana. 2017. Social networks in the context of community response to disaster: Study of a cycloneaffected community in coastal West Bengal, India. International Journal of Disaster Risk Reduction 22: 281-296.

Molyneux, M. 2006. Mothers and the service of the new policy agenda: Progresa/Oportunidades, Mexico's conditional transfer programme. Social Policy and Administration 40(4): 425-449.

Mugandani, R., M. Wuta, A. Makarau, and B. Chipindu. 2012. Reclassification of agro-ecological regions of Zimbabwe in conformity with climate variability and change. African Crop Science Journal 20(2): 361-369.

Oxfam. 2019. Cyclone Idai in Zimbabwe: An analysis of policy implications for post-disaster institutional development to strengthen disaster risk management. Oxford: Oxfam International.

Preston, J., C. Chadderton, K. Kitagawa, and C. Edmonds. 2015. Community response in disasters: An ecological learning framework. International Journal of Lifelong Education 34(6): 727-753.

Rajeev, M.M. 2014. Sustainability and community empowerment in disaster management. International Journal of Social Work and Human Services 2(6): 207-212.
Simba, F.M. 2018. Zimbabwe's preparedness in managing meteorological disasters: A case of applying disaster risk management in managing impacts of climate change. Journal of Geography and Natural Disasters 8(3). https://doi.org/10.4172/2167-0587. 1000231.

Siyongwana, P.Q., D. Heinjie, and A. Tele. 2015. Vulnerability and coping strategies of low income communities to flood hazards, Missionvale, South Africa. Journal of Human Ecology 52(1-2): 104-115.

Smith, D.I., and J.W. Handmer. 1984. Urban flooding in Australia: Policy development and implementation. Disasters 8(2): $105-117$.

Speller, G. 2005. Improving community and citizen engagement in flood risk management decision making, delivery and flood response. R and D technical report (SC040033/SR3). Bristol: Environment Agency.

Troy, D.A., A. Carson, J. Vanderbeek, and A. Hutton. 2008. Enhancing community-based disaster preparedness with information technology. Disasters 32(1): 149-165.

Twigg, J. 1999. The age of accountability?: Future community involvement in disaster reduction. Australian Journal of Emergency Management 14(4): 51-58.

Varda, D.M., R. Forgette, D. Banks, and N. Contractor. 2009. Social network methodology in the study of disasters: Issues and insights prompted by post-Katrina research. Population Research and Policy Review 28(1): 11-29.

Yila, O., E. Weber, and A. Neef. 2013. The role of social capital in post-flood response and recovery among downstream communities of the Ba River, Western Viti Levu, Fiji Islands. In Risks and conflicts: Local responses to natural disasters, ed. A. Neef, and R. Shaw, 79-107. Bingley: Emerald Publishers.

ZimStat (Zimbabwe National Statistical Agency). 2013. Census 2012, Manicaland Province. Harare: ZimStat.

Zubir, S.S., and H. Amirrol. 2011. Disaster risk reduction through community participation. In Management of Natural Resources, Sustainable Development and Ecological Hazards (WIT Transactions on Ecology and the Environment 148), ed. C.A. Brebbia, and S.S. Zubir, 195-206. Ashurst, New Forest, U.K.: Wessex Institute of Technology Press. 